\title{
EFFECT OF SHORT SAFFIL FIBRES AND SiC PARTICLES ON MECHANICAL PROPERTIES OF MAGNESIUM ALLOYS
}

The high temperature mechanical behaviour of composites with the AZ91 and AS21 magnesium alloys matrix, reinforced with short Saffil fibres and SiC particles were investigated. Samples were deformed in compression in the temperature range from room temperature to 300 ${ }^{\circ} \mathrm{C}$. The yield stress and the maximum stress of true stress-true strain curves decrease with increasing temperature. Light and electron microscopy were used for study of the microstructure of composites. Possible hardening and softening mechanisms are discussed. The increased dislocation density and the shear stress at reinforcing phase/matrix interfaces were found as the most important contributions to the strengthening.

Keywords: Magnesium alloys; Composites; Mechanical properties; Strengthening; Interface; Dislocation motion

\section{Introduction}

Several magnesium-based metal matrix composites (MMCs) have been developed over the last decade for potential use as lightweight high-performance materials [1]. It is well established that the microstructures and the mechanical properties of MMCs are strongly affected by the nature of the interfaces between the matrix and the reinforcement. Strengthening in metals and alloys reinforced by fibres or particles were analysed in many papers with the aim to find the correlation between mechanical properties and microstructural characteristics of composites. In spite of many attempts there is no generally accepted model for metal matrix composites strengthening. It is probably due to very complex character of the problem. Many factors and mechanisms play role and synergetic operation of these mechanisms has been not sufficiently studied. Investigations of mechanical and physical properties of MMC (among them magnesium alloys based composites) are important not only for applications but also for better understanding of the processes responsible for their behaviour.

In literature there are three types of models explaining mechanical properties of MMCs. Models resulting from the continuum mechanics are either numerical, typically finite element, models, or analytical effective medium schemes (for example [2-6]). Dislocation approach has a possibility to predict the interaction of individual dislocations with stress fields, solute atoms, and precipitates, grain boundaries and reinforcing phase fibres or particles. Continuum plasticity ignores the details of slip on an atomic level and uses constitutive equations to relate stress and strain (or strain rate) in the matrix. The properties of the reinforcing phase influence dislocation behaviour and the mechanical properties of composites. While the intrinsic mechanical and physical properties of the reinforcement (stiffness, strength, and thermal expansion) are dictated by its chemical nature, the geometric and topological parameters of the reinforcement (shape, size, volume fraction, spatial orientation, and distribution) can be altered during processing. Trojanová et al. [7] discussed various strengthening mechanisms in $\mathrm{Mg}$ alloys reinforced by short Saffil fibres. The most important contributions were found to be the load transfer from the matrix to the fibres and the influence of the increased dislocation density arising from internal thermal stresses. Other possible mechanisms do not influence the level of deformation stresses in a significant manner.

The objectives of the present paper are to study the deformation behaviour of the AZ91 and AS21 magnesium alloys based hybrid composites and to discuss possible contribution of Saffil ceramic fibres and $\mathrm{SiC}$ particles to strengthening as well as softening of these materials.

\section{Experimental procedures}

Commercial AZ91 (9Al-1-Zn-0.1Mn-balance Mg) and AS21 (2.2Al-1Si-0.1Mn-balance Mg-in wt\%) alloy were used as the matrix material. The alloys were reinforced with $\delta-\mathrm{Al}_{2} \mathrm{O}_{3}$ short fibres (Saffil) and equiaxial $\mathrm{SiC}$ particles. The preforms consisting of $\mathrm{Al}_{2} \mathrm{O}_{3}$ short fibres showing a planar isotropic fibre distribution, $\mathrm{SiC}$ particles and a binder system (containing $\mathrm{Al}_{2} \mathrm{O}_{3}$ and starch) were preheated to a temperature higher than the melt temperature of alloy and then inserted into a preheated die. The two-stage application of the pressure resulted in MMCs with a fibre volume fraction from approximately $5 \mathrm{vol}$. \% of fibres and $15 \mathrm{vol} . \%$ of SiC. The mean fibre length and fibre diameter (measured after squeeze

\footnotetext{
* Z. Trojanova, Z. Szaraz, V. Gartnerova

Department of Physics of Materials, Faculty Mathematics and Physics, Charles University Prague, Czech Republic, E-mail: ztrojan@met.mff.cuni.cz
} 
casting) were $\sim 78 \mu \mathrm{m}$ and $\sim 3 \mu \mathrm{m}$, respectively. Sharply shaped $\mathrm{SiC}$ particles exhibited size of about $10 \mu \mathrm{m}$. Composites with the AZ91 matrix alloy (AZ91h) were thermally treated according to Polmear [8] $\left(413{ }^{\circ} \mathrm{C}\right.$ for 18 hours followed by quenching and artificial aging at $168{ }^{\circ} \mathrm{C}$ for 8 hours). Samples with AS21 matrix alloy (AS21h) were not thermally treated. Samples for compression tests were machined with dimensions of $5 \times 5 \times 10 \mathrm{~mm}^{3}$ with the plane of Saffil fibres oriented parallel to the stress axis. Compression tests were carried out in a universal INSTRON testing machine in displacement control at a nominal strain rate of $8.3 \times 10^{-5} \mathrm{~s}^{-1}(\mathrm{AZ} 91 \mathrm{~h})$ and $2.7 \times 10^{-4} \mathrm{~s}^{-1}(\mathrm{AS} 21 \mathrm{~h})$ at temperatures between room temperature and $300{ }^{\circ} \mathrm{C}$. The temperature in the furnace was kept with an accuracy of $\pm 1^{\circ} \mathrm{C}$. The yield strength of the composites was determined by an offset method at $0.2 \%$ $\left(\sigma_{02}\right)$ plastic strain. Sections of composite castings were polished and examined by the light microscope Olympus and substructure of composites by the transmission electron microscopy (TEM).

\section{Results}

Fig. 1 shows a microstructure of AZ91h composite after T6 heat treatment. The observed structure consists of solid solution of aluminium in magnesium ( $\delta$-phase), electron compound $\mathrm{Al}_{12} \mathrm{Mg}_{17}$ ( $\gamma$-phase) and discontinuous precipitate (lamellae of $\gamma+\delta$ phase). Saffil fibres are distributed randomly in the planes parallel to the compression direction. From the micrograph it is to see that $\mathrm{SiCp}$ are distributed non-uniformly. Characteristic feature of the AS21 composite microstructure is $\mathrm{Mg}_{2} \mathrm{Si}$ phase having a characteristic Chinese-script form [9]. Microstructure of the AS21h is introduced in Figure 2. Saffil fibres as well as $\mathrm{SiC}$ particles are visible. It is obvious that $\mathrm{SiC}$ particles are not uniformly distributed in the matrix; in many cases they form clusters.

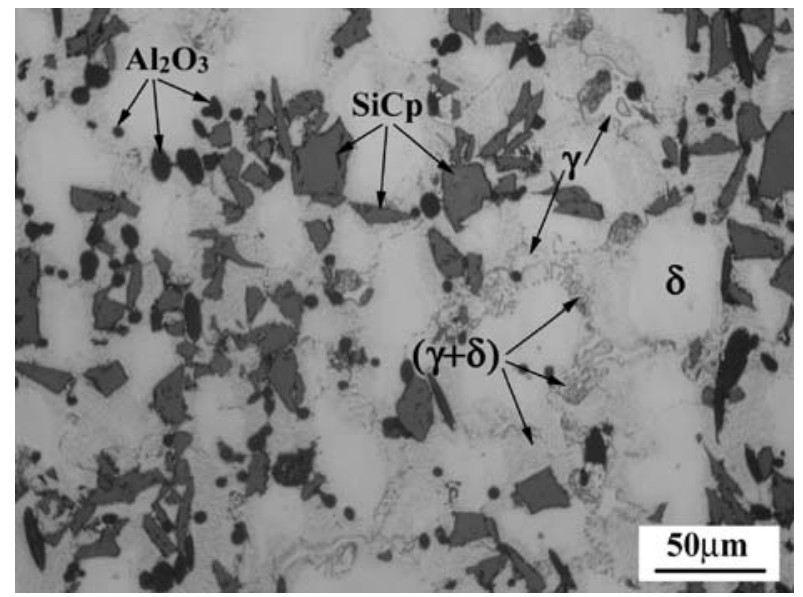

Fig. 1: Representative microstructure of AZ91 hybrid composite.

Fig. 3 shows the true stress-true strain curves obtained for AZ91h composite deformed at various temperatures. Samples were deformed either to fracture or at higher temperatures to predetermined strains. The fracture occurred up to $200{ }^{\circ} \mathrm{C}$, however, at $250{ }^{\circ} \mathrm{C}$ and $300{ }^{\circ} \mathrm{C}$ the deformation was interrupted at about 0.25

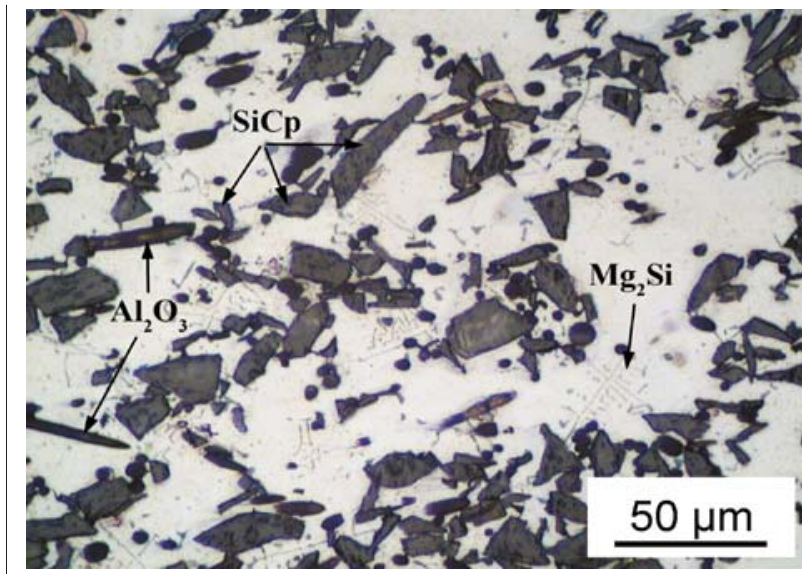

Fig. 2: Microstructure of hybrid composite with Saffil fibres and $\mathrm{SiC}$ particles. Small precipitates in the form of Chinese script are visible.

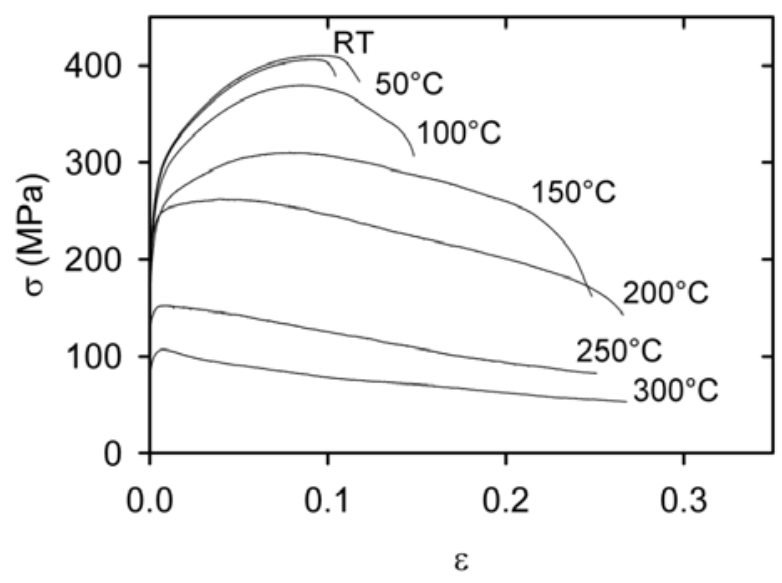

Fig. 3: Stress strain curves obtained for AZ91h and various temperatures.

of true strain. Both characteristic stresses (the yield stress $\sigma_{02}$ and the maximum stress $\sigma_{\max }$ ) are shown in Fig. 4 . The yield stress $\sigma_{02}$

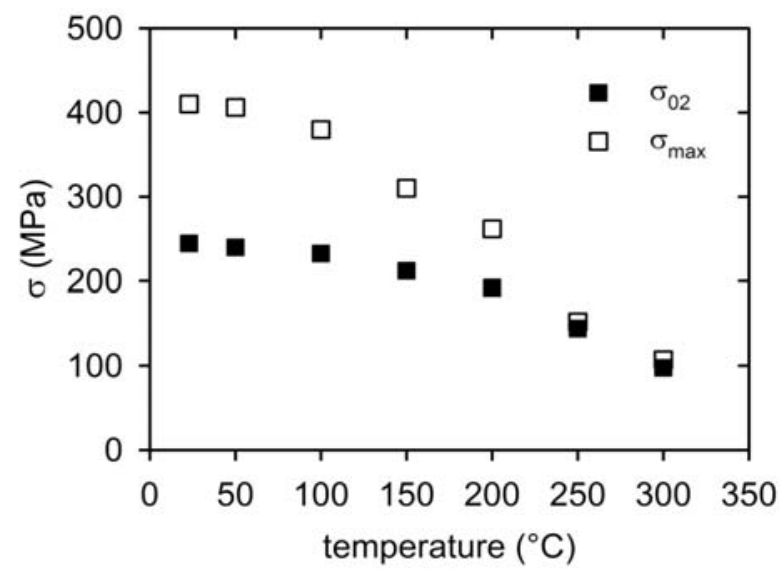

Fig. 4: Temperature dependence of the yield stress and the maximum stress obtained for AZ91h. 
decreases slightly with temperature up to $150{ }^{\circ} \mathrm{C}$ and then, for higher temperatures the yield stress decreases more rapidly. The measured difference between the yield and maximum stress is at room temperature about $170 \mathrm{MPa}$ and it decreases with increasing temperature to about $10 \mathrm{MPa}$ at $300{ }^{\circ} \mathrm{C}$. The small difference between the yield stress and the maximum stress reflects the flat character of the stress strain curves.

Similar stress-strain curves were obtained for AS21h composite as it as demonstrated in Fig. 5. Significant strain hardening was estimated at temperatures up to $150{ }^{\circ} \mathrm{C}$. At temperatures higher than $150{ }^{\circ} \mathrm{C}$ observed curves have a steady state character. Ductility is about $10 \%$ at lower temperatures and it increases with increasing temperature. Temperature dependence of the yield stress as well as the maximum stress is introduced in Fig. 6. The yield stress exhibits a local maximum at $50{ }^{\circ} \mathrm{C}$. Such small local maximum in

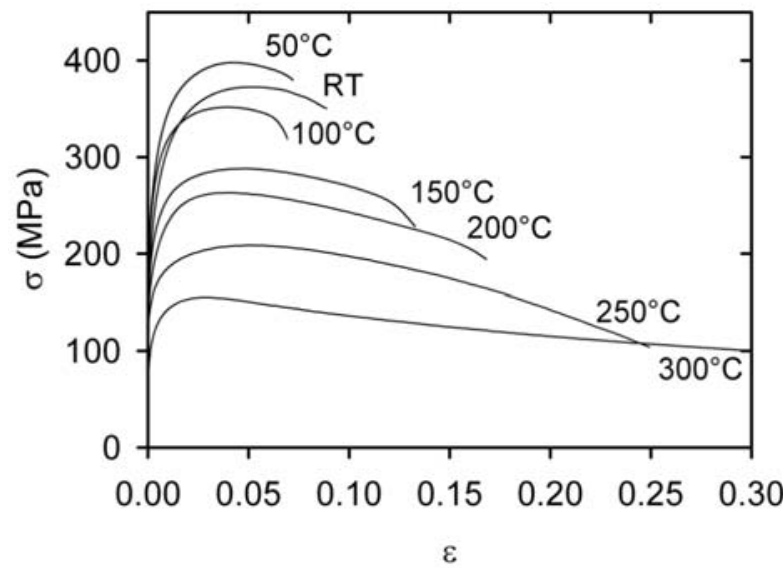

Fig. 5: Stress strain curves obtained for AS21h and various temperatures.

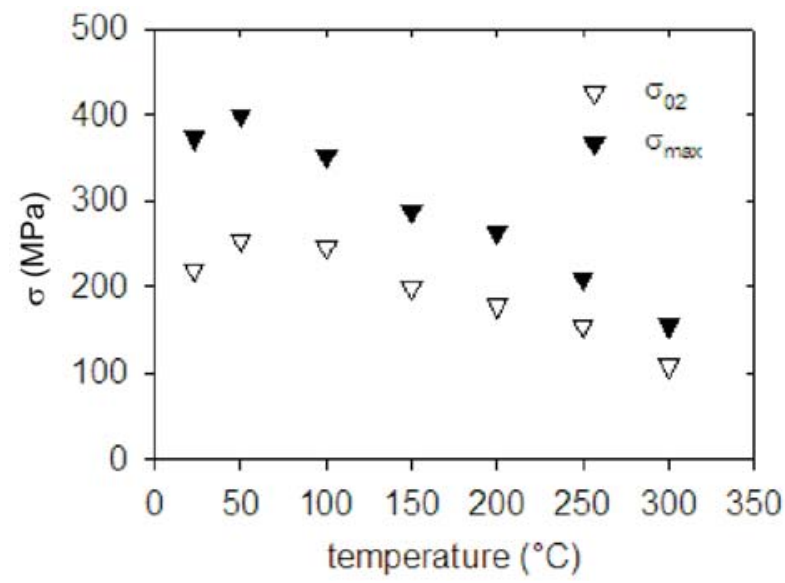

Fig. 6: Temperature dependence of the yield stress and the maximum stress obtained for AS21h.

the temperature dependence of the yield stress was observed also in other magnesium alloys (AZ91, LA45) [10-12]. This loca maximum in the temperature dependence of the yield stress is very probably a result of the dynamic strain ageing phenomenon, where mobile solute atoms interact with dislocations.

The influence of the reinforcing phase (fibres and particles) on the yield stress is well apparent from Fig. 7 for AZ91h and in Fig. 8 for AS21h comparing with the unreinforced alloy. From both figures it can be seen the major effect of fibres and particles at room temperature and a decreasing influence of the reinforcing phase at temperatures higher.

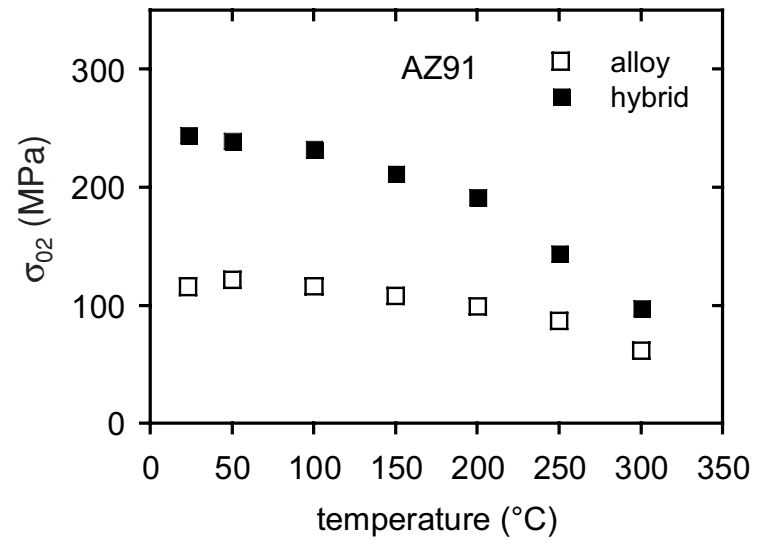

Fig. 7: Comparison of the yield stress of AZ91 composite and alloy.

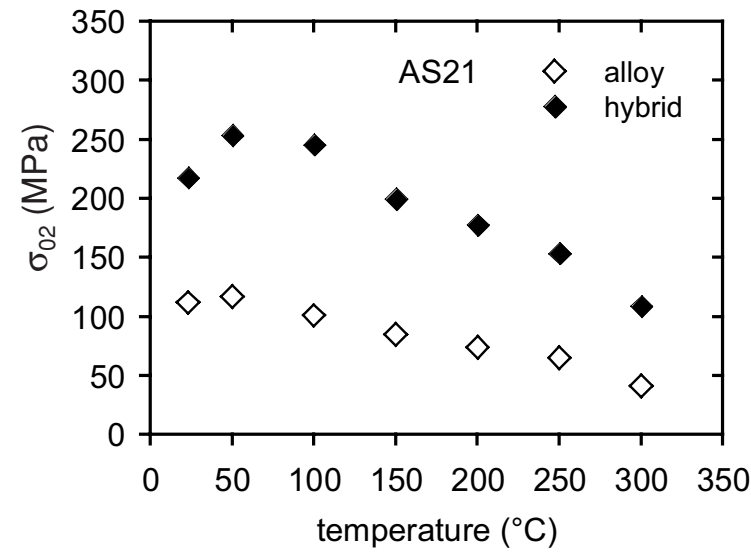

Fig. 8: Comparison of the yield stress of AS21 composite and alloy.

\section{Discussion}

\subsection{Hardening mechanisms}

Load transfer

The load transfer from matrix to fibres can be described by the shear lag theory, which assumes that the load transfer occurs between reinforcement and the matrix by means of shear stress at the interface between the reinforcing phase and matrix. According to this mechanism, the fibre can act as a "reinforcement" to carry 
some of the load. Several authors [13-16] considered the shear lag model. The flow stress $\sigma_{L T}$ necessary for composite deformation due to load transfer can be calculated as [17]:

$$
\sigma_{L T}=\sigma_{m}\left[1+\frac{(L+t) A}{4 L}\right] f+\sigma_{m}(1-f),
$$

where $\sigma_{m}$ is the stress in the matrix, $L$ is the fibre size in the direction of the applied stress, $\mathrm{t}$ is the fibre size in the perpendicular direction, $A$ is the fibre aspect ratio $(L / t)$ and $f$ is the volume fraction of reinforcement (fibres). The model is based on the simplifying assumption of a uniform matrix deformation and therefore, yields a very simplified expression for stiffness and strength contribution. Except the stress transfer from the matrix to the reinforcing phase, fibres or particles, the shear lag model does not account for the contributions from effects, which are associated with the inhomogeneous matrix behaviour, resulting in enhanced dislocation density and residual thermal stresses. For equiaxial particles, an increase in the yield stress due to load transfer $\Delta \sigma_{L T}$ may be given by

$$
\Delta \sigma_{L T}=\sigma_{m} 0.5 f .
$$

The strengthening component $\Delta \sigma_{L T}$, depends on the reinforcement volume fraction $f$.

Enhanced dislocation density.

Typical large difference between coefficients of thermal expansion (CTE) of the matrix and ceramic reinforcement $\Delta \alpha$ is a very important factor for the deformation behaviour of composites with a metallic matrix. CTE of a ceramic reinforcement is smaller than that of most metallic matrices. When a metal matrix composite is cooled from a higher temperature to room temperature misfit strains occur because of differential thermal contraction at the interface. These strains induce thermal stresses that may be higher than the yield stress of the matrix. The thermal stresses may be sufficiently high to generate new dislocations at the interfaces between the matrix and the reinforcements. Therefore, after cooling the composite, the dislocation density in the matrix increases. The density of newly generated dislocations, near reinforcement fibres or particles, can be calculated as [18]:

$$
\rho_{T}=\frac{B f \Delta \alpha \Delta T}{b(1-f)} \frac{1}{t},
$$

where $t$ is a minimum size of the reinforcing phase particles or fibres, $b$ is the magnitude of the Burgers vector of the newly created dislocations, $B$ is a geometrical constant $(B=10$ for fibres and ( $B=12$ for particles), $\Delta \alpha \Delta T$ is the thermal strain. When the thermal stresses achieve the yield stress, plastic zones can be formed in the matrix near the interfaces, especially, in the vicinity of fibre ends. We assume that the higher dislocation density arises in composites during the fabrication procedure. Increased dislocation density was detected by the internal friction measurements [19] and also directly observed by the means of the TEM [20].

Plastic deformation is generation, movement and storage of dislocations. Dislocations are stored at obstacles arising due to dislocation interaction (statistical dislocations) or they are required for the compatible deformation of various parts of the crystal constrained within its surroundings. These dislocations that are stored due to incompatibility of deformation are dislocations geometrically necessary. The density of dislocations geometrically necessary can be linked to the average strain gradient present in the microstructure and may be expressed as [21]

$$
\rho_{G}=\frac{f 8 \varepsilon_{p}}{b t},
$$

where $\varepsilon_{p}$ is plastic strain. In the case of MMCs with the ceramic reinforcing phase, the incompatibility in deformation between the plastically deforming matrix and essentially rigid reinforcement leads to creation of strong strain gradients in the metallic matrix. The influence of the geometrically necessary dislocations increases with increasing strain.

Introducing reinforcing phase into the metal matrix influences not only the densities of the thermally formed and geometrically necessary dislocations, but also the dislocation stored at reinforcements during deformation. Considering these effects, the total dislocation density in composites can be written:

$$
\rho_{\text {total }}=\rho_{T}+\rho_{G}+\left(\rho_{S}+\rho_{a}\right) \text {, }
$$

where $\rho_{S}$ is the statistically stored dislocation density in the unreinforced matrix, $\rho_{a}$ is the diminished part of the statistically stored dislocations due to the addition of reinforcing phase. The strengthening in the matrix alloy is attributed to the deformation resistance induced by the reinforcing phase. According to the Taylor relation, the contribution to the total stress due to the presence of dislocations in the matrix may be written:

$$
\Delta \sigma_{D}=\alpha_{1} \psi G b\left(\rho_{T}+\rho_{G}+\rho_{s}+\rho_{a}\right)^{L / 2},
$$

where $\alpha_{1}$ is a constant, $\psi$ is the Taylor factor and $G$ is the shear modulus. This higher matrix dislocation density as well as the reinforcement/matrix interfaces can provide high diffusivity paths in a composite. The higher dislocation density would also affect the precipitation kinetics in a precipitation hardenable matrix.

\section{Orowan strengthening}

The yield stress is characterised by the state when the matrix plastic flow is developed. Fibres in the matrix are obstacles for dislocation motion. Therefore, the stress necessary for motion of dislocations in the composite is higher than in the matrix without fibres. We consider a similar mechanism as in the case of strengthening by incoherent particles, i. e. Orowan strengthening. It is caused by the resistance of closely spaced hard fibres to the passing of dislocations. Asides from fibres, dislocations overcome stresses from dislocation pile-ups in the vicinity of the fibres. For strengthening caused by this mechanism, one may use the expression as a first approximation [22]

$$
\Delta \sigma_{o R}=\left(\frac{G b}{\Lambda}+\frac{5}{2 \pi} G f \varepsilon_{p}\right)
$$

where $\Lambda$ is the distance between fibres and $\varepsilon_{p}$ is plastic deformation. It is widely accepted, however, that Orowan strengthening is 
not significant for metal matrix composites because the reinforcements are coarse and the interfibre spacing is large. In our case, if $\Lambda$ measures in units of $\mu \mathrm{m}$, the increase of the yield stress $\Delta \sigma_{O R}$ is not significant.

\section{Grain size refinement}

Discontinuously reinforced composites usually have very fine grains, smaller than their unreinforced matrices [23]. The contribution to the yield stress can then be estimated using the HallPetch relation, which relates the yield stress enhancement to grain size

$$
\Delta \sigma_{G S}=K_{y}\left(d_{2}^{1 / 2}-d_{1}^{1 / 2}\right),
$$

where $K_{y}$ is the Hall-Petch constant, $d_{1}$ and $d_{2}$ the grain sizes of the coarse and fine grained alloy or composite, respectively. Subgrains may contribute to the composite strengthening in the similar way as the grain boundaries. It should be mentioned that Arsenault and co-workers [24] observed smaller subgrain size in Al composites reinforced by $\mathrm{SiC}$ particles. They suggested other contribution to the strengthening due to a reduction of dislocation cell size.

\section{Thermally induced plastic flow}

Chmelík and co-workers [25-27] studied induced plastic strains in $\mathrm{Mg}$ alloy based composites using non-destructive methods. Acoustic emission was detected in situ during thermal cycling of composites between room temperature and increasing upper temperature of the thermal cycle in a dilatometer equipped with a radiant furnace. After each cycle the residual strain was measured. As a consequence of the fabrication at elevated temperatures, both components of the metal matrix composite i.e. matrix as well as reinforcement are in equilibrium only at the manufacturing temperature. They exhibit internal thermal stresses at room temperature whose magnitude should be close to a minimum stress necessary for matrix micro-strain. The matrix is under tensile stresses and the reinforcement is under compressive stresses. When a MMC is heated up, the internal tensile stress acting on the matrix decreases to zero and on further heating compressive stresses build up. On cooling the internal stresses will behave in an opposite manner.

\section{Residual thermal stresses}

At higher temperatures, stresses can achieve the yield stress and the composite is plastically deformed only owing to the temperature cycling. Thermal stresses directly near the matrix-fibre interphase may be calculated in the simple approximation [28] as

$$
\sigma_{T S}=\frac{E_{f} E_{M}}{\left(E_{f} f+E_{M}(1-f)\right)} f \Delta \alpha \Delta T,
$$

where $E_{f}$ and $E_{M}$ are Young's moduli of the reinforcing phase fibres or particles and the matrix, respectively. Relation (9) estimates thermal stresses directly at the interphase. In a certain distance from the fibre, the thermal stress is lower because it decreases with the distance. Volume-averaged residual stresses reach in the matrix their maximum value [28]

$$
\left\langle\sigma_{m}\right\rangle_{\max }=\frac{2}{3} \sigma_{y m} \ln \left(\frac{1}{f}\right) \frac{f}{1-f},
$$

where $\sigma_{y m}$ is the yield stress in the matrix.

\section{Combination of strengthening terms}

Several schemes have been proposed for addition of the various strengthening terms. The most commonly accepted are those reviewed by Lilholt [29] who differentiates between the range of magnitude of the strengthening mechanisms and their relative strength. In principle, computer models are required to sample statistically the different contributions. Clearly, stress contributions, which act more or less uniformly throughout the matrix must be superimposed linearly, whereas mechanisms of similar strengthening ability, which act unevenly throughout the matrix, are most suitably combined as the square root of the sum of the squares [30].

\section{Comparison with experimental results}

All individual contributions to the strengthening for both materials calculated using constants introduced in Table 2 are summarised in Table 1 together with the linear and quadratic sum. Comparison with the experimental values of the yield stress obtained for room temperature for both materials showed that the linear sum gave the higher values of the total stress necessary for the deformation of the hybrid composites while the quadratic sum is lower than the stress estimated experimentally. It is also necessary to note that models for each mechanism are constructed for the perfect bonding between the matrix and the reinforcing phase. If the bonding is not perfect the contribution to the strengthening is lower. From this point of view the linear sum seems to be more suitable for the estimation of the ceramic phase reinforcing effect. Non-uniform distribution of reinforcing phase (fibres and particles) must be also taken into account. As it follows from Table 1, the increased dislocation density is in the most important contribution to strengthening.

Contribution of various strengthening

Tab. 1 mechanisms to the yield stress of composites

\begin{tabular}{|l|c|c|}
\hline & AS21 & AZ91 \\
\hline$\sigma_{02}$ alloy $(\mathrm{MPa})$ & 112 & 116 \\
\hline$\Delta \sigma_{L T}(\mathrm{MPa})$ & 28.7 & 30 \\
\hline$\Delta \sigma_{D}(\mathrm{MPa})$ & 69 & 69 \\
\hline$\Delta \sigma_{O R}(\mathrm{MPa})$ & 5 & 5 \\
\hline$\Delta \sigma_{G S}(\mathrm{MPa})$ & 10 & 15 \\
\hline$\left\langle\sigma_{m}\right\rangle_{\text {max }}(\mathrm{MPa})$ & 30 & 31 \\
\hline$\sigma_{\text {total }}(\mathrm{MPa})($ linear $)$ & 254.7 & 266 \\
\hline$\sigma_{\text {total }}(\mathrm{MPa})($ root of sum of squares $)$ & 193.3 & 198.9 \\
\hline$\sigma_{02 \text { experimental }}(\mathrm{MPa})$ & 218 & 244 \\
\hline
\end{tabular}




\begin{tabular}{|c|c|c|c|c|c|c|c|c|}
\hline $\begin{array}{c}\alpha(\mathrm{AZ91}) \\
\left(\mathrm{K}^{-1}\right)\end{array}$ & $\begin{array}{c}\alpha(\mathrm{AS} 21) \\
\left(\mathrm{K}^{-1}\right)\end{array}$ & $\begin{array}{c}\alpha(\mathrm{Saffil}) \\
\left(\mathrm{K}^{-1}\right)\end{array}$ & $\begin{array}{c}\alpha(\mathrm{SiC}) \\
\left(\mathrm{K}^{-1}\right)\end{array}$ & $\begin{array}{c}K_{y}(\mathrm{Mg}) \\
\left(\mathrm{MPam}^{-3 / 2}\right)\end{array}$ & $\begin{array}{c}\alpha 1 \\
(\mathrm{hcp})\end{array}$ & $\begin{array}{c}\text { Taylor factor } \\
\psi\end{array}$ & $\begin{array}{c}b \\
(\mathrm{~m})\end{array}$ & $\begin{array}{c}G \\
(\mathrm{GPa})\end{array}$ \\
\hline 26 & 30 & $6 \times 10^{-6}$ & $6.6 \times 10^{-6}$ & 0.28 & 0.35 & 6 & $3.21 \times 10^{-10}$ & 17 \\
\hline$[9]$ & {$[9]$} & {$[31]$} & {$[31]$} & {$[32]$} & {$[33]$} & {$[34]$} & & \\
\hline
\end{tabular}

\subsection{Recovery mechanisms}

The observed steady state character of the stress strain curves obtained at elevated temperatures, where maximum stress was achieved already at lower strain and subsequent stress is constant or decreases, indicates an operating of some recovery mechanism/-s. Cross slip in prismatic or pyramidal planes is very probably the main recovery mechanism. The recovery mechanisms are strongly thermally activated. An increased activity of prismatic and pyramidal slip systems with $\langle c\rangle$ and $\langle c+a\rangle$ dislocations, respectively, at higher temperatures provides explanation for the observed decrease of the flow stress. Cross-slip as well as the subsequent annihilation of dislocations results in a decrease in the work hardening rate.

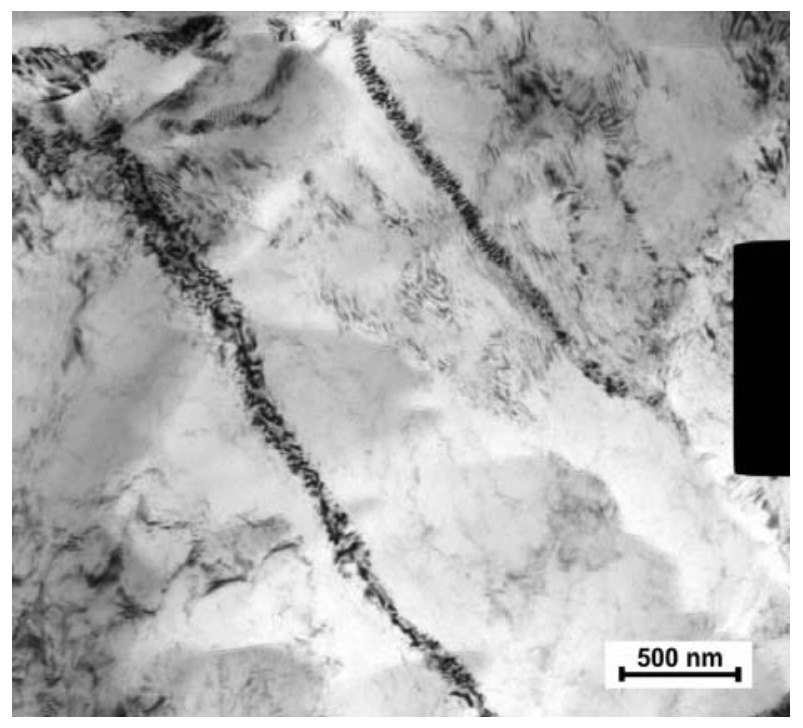

Fig. 9: Dislocation pile-ups in deformed AS21h composite.
Plastic deformation in a composite begins by developing the strain in the vicinity of fibres or particles, where dislocation density is higher than elsewhere in the matrix. Dislocations cannot pass through the reinforcing fibres or particles without leaving loops around fibres. This passing mechanism is similar to the Orowan mechanism and it is also athermal. Dislocations pile-ups formed can act as stress concentrators. The screw dislocation components locally cross slip, forming superjogs having a height of about fibre diameter. At higher temperatures, edge components are able to climb. In both cases, dislocations may then annihilate in neighbouring slip planes. Possible annihilation of dislocations may be also supported by the interfacial diffusion of vacancies in the thin layer at the matrix-fibre interface [35]. Dislocation pile-ups formed in the vicinity of reinforcing phase were observed by TEM in deformed composites as it is shown for the AS21h composite in Fig. 9.

\section{Conclusions}

Ceramics fibres and particles influence significantly mechanical properties of composites with the AS21 and AZ91 matrix. As it follows from the Table 1 the significant strengthening mechanisms in composites studied are increased dislocations density and the load transfer in which the part of the external load within the matrix is transferred to reinforcement. While the shear lag model used supposes a perfect bonding at the interface between matrix and reinforcing phase, the real values of this contribution are very probably lower. Different precipitates in the monolithic alloy and in the matrix of the hybrid composite contribute by different way to the precipitation hardening in the matrix. Higher thermal stability of $\mathrm{Mg} 2 \mathrm{Si}$ precipitates is very probably reason for better high temperature properties of the AS21 hybrid composite.

\section{Acknowledgements}

The authors acknowledge financial support of the Grant Agency of the Czech Republic under grant 106/06/1354. The authors are grateful also for the support offered by the Czech and Slovak authorities under the Exchange Programme MEB 0808116.

\section{References}

[1] FRITZE, C., BEREK, H., KAINER, K.U., MIELKE, S., WIELAGE B. in: MORDIKE, B.L., KAINER, K. U. (Eds.): Magnesium Alloys and their Applications, Werkstoff-Informationsgesellschaft, Oberursel, 1998, 635.

[2] BAO, G., HUTCHINSON, J.W., McMEEKING, R.M.: Acta Metall. Mater. 1991, 39, 1871.

[3] CHRISTMAN, T., NEEDLEMAN, A., SURESH, S.: Acta Metall. 37, 1989, 3029.

[4] SHEN, Y.-L., FINOT, M., NEEDLEMAN, A., SURESH, S.: Acta Metall. Mater. 43, 1995, 1701.

[5] MUELlER, R., MORTENSEN, A.: Acta Mater. 54, 2006, 2145.

[6] TORQUATO, S.: Random heterogeneous materials: microstructure and macroscopic properties. New York, Springer, 2002. 
[7] TROJANOVA, Z., GARTNEROVA, V., LUKAC, P., DROZD, Z.: J. Alloys Comp. 378, 2004, 19.

[8] POLMEAR, I.J., MORDIKE, B.L., HEHMANN, F. (Eds.) in: Magnesium Alloys and Their Applications, DGM, Oberursel, $1992,201$.

[9] ADVESIAN, M.M., BAKER, H. (Eds.): Magnesium and Magnesium Alloys. ASTM International Materials Park 2000.

[10] TROJANOVA, Z., SZARAZ, Z: Mater. Sci. Forum 482, 2005, 363.

[11] TROJANOVA, Z., LUKAC, P., GABOR, P., DROZD, Z., MATHIS, K.: Kovove Mater. 39, 2001, 368.

[12] DROZD, Z., TROJANOVA, Z., GÄRTNEROVA, V.: Magnesium Alloys and Their Applications, Ed. KAINER, K. U., DGM, Willey 2003, 122.

[13] FUKUDA, H., CHOU, T. W.: J. Compos. Mater. 15, 1981,79.

[14] NARDONE, V. C., PREWO, K. M.: Scripta Metall. 20, 1986, 43.

[15] CLYNE, T. W.: Mater. Sci. Eng. A, 122, 1989, 183.

[16] TAYA, M., ARSENAULT, R. J.: Scripta Metall. 21, 1987, 349.

[17] AIKIN JR., R. M., CHRISTODOULOU, L.: Scripta Metal. Mater. 25, 1991, 9.

[18] ARSENAULT, J.R., SHI, N.: Mater. Sci. Engn. 81, 1986, 853.

[19] TROJANOVA, Z., LUKAC, P., RUDAJEVOVA, A.: Mater. Sci. Engn. A, 370, 2004, 542.

[20] TROJANOVA, Z., SZARAZ, Z., LABAR, J., LUKAC, P.: J. Mater. Process. Techn. 162-163, 2005, 131.

[21] ASHBY, M.F.: Phil Mag. 21, 1970, 399.

[22] SCATTERGOOD, R. O., BACON, D.: Phil. Mag. A31, 1975, 179.

[23] MILLER W. S., HUMPHREYS F. J.: Scripta Metall. Mater. 25, 1991, 33.

[24] ARSENAULT, R. J., WANG, L., FENG, C. R.: Acta Metall. Mater. 39, 1991, 47.

[25] CHMELIK, F., LUKAC, P., KIEHN, J., MORDIKE, B. L., KAINER, K. U., LANGDON, T. G.: Mater. Sci. Eng. A 325, $2002,320$.

[26] CHMELIK, F., KIEHN, J., LUKAC, P., KAINER, K. U., MORDIKE, B. L.: Scripta Mater. 38, 1998, 81.

[27] CHMELIK, F., LUKAC, P., KUDELA, S., KIEHN, J., MORDIKE, B. L., KAINER, K. U.: Magnesium Alloys and their Applications. Ed. KAINER, K.U., Wiley-VCH Weinheim 2000, 229.

[28] DELANNAY, F.: Comprehensive Composite Materials, CLYNE, T.W. (Ed.), Vol. 3, Elsevier, Amsterdam, $2000,341$.

[29] LILHOLT, N.: Deformation of Multi-Phase and Particle Containing Materials. Eds. BILDE SORENSON, J. B., HANSEN, N., HORSEWELL, A., LEFFERS, T., LILHOLT, H., Riso Nat. Lab. 1983, Roskilde, 381.

[30] CLYNE, T., WHITHERS, J. P.: An Introduction to Metal Matrix Composites, Cambridge Press, Cambridge 1993, 94.

[31] Handbook of Chemistry and Physics. (Ed. D.R. Lide), $73^{\text {rd }}$ edition. CRC Press, 1992/1993.

[32] MABUCHI, M., KUBOTA, K. HIGASHI, K.: Mater. Trans.JIM 36, 1995, 1249.

[33] LAVRENTEV, F. F., POKHIL, Y. A., ZOLOTUKHINA: I. N.: Mater. Sci. Engn. 32, 1978, 113.

[34] ARMSTRONG, R. W.: Acta metall. 16, 1968, 347.

[35] SHEWFELT, R. S. W., BROWN, L. M.: Phil. Mag. 35, 1977, 945. 